\title{
La problemática del tiempo en «Walden»
}

\author{
Honesto Herrera Soler
}

Cuando quiera que leemos una obra literaria desde un punto de vista crítico, tendemos a estudiar el aspecto simbólico, estructural, narrativo o posibles planos de lectura. En este artículo, aun consciente de que me aparto de los patrones de la crítica actual, he querido tratar la «problemática del tiempo en Walden», llevado de la confianza de que el estudio de $W$ alden, desde esta perspectiva, es el factor que más luz nos da para comprender la obra de Thoreau.

Probablemente necesitaremos de una segunda o tercera lectura de Walden para darnos cuenta de la importancia del tiempo en la obra, para ver cómo Thoreau llega a «dominar» el tiempo, cómo llega a asimilar el significado que se le da en la filosofía hindú «al despertar». De aquí que un estudio sobre el proceso de la conquista del tiempo y de las múltiples acepciones que recibe el concepto del tiempo nos permita ver con mayor claridad la unidad de la obra dentro de la diversidad de capítulos. De hecho, Thoreau hubiera podido haber escrito un capítulo más, titularlo «el tiempo»e incrustarlo en cualquier lugar antes de la «Conclusio». Dicho capítulo no desmerecería nada respecto de cualquier otro, llámese «Readings», «Economy»o «Spring».

Observamos que en cualquier novela que cae en nuestras manos, la mayor parte de las veces hay un desarrollo progresivo del «fenómeno tiempo»con sus respectivos «flashbacks» $\mathrm{y}$ «forwards». Esta observación es manifiesta incluso en obras que guardan gran relación con Walden, como puede ser el caso de $W$ alden $I I$, en el que Skinner nos presenta sus ideas y experiencias de una manera progresiva, de acuerdo con el período de tiempo que transcurre de un miércoles a un lunes de la semana siguiente. No sucede lo mismo con Walden, Thoreau tiene una idea distinta del tiempo, una idea original y personal, que para llegar a entenderla nos exigirá que hagamos un estudio desde distintos ángulos. Sólo 
así podremos identificar ese capítulo que nunca escribió de una manera expresa, pero que está implícito en $W$ alden; cuya existencia es similar a la de aquellos momentos de su vida que no pudo escribir y vivir al mismo tiempo:

«My life has been the poem I would have writ

But I could not both live and utter it» ${ }^{1}$

Las alusiones temporales se multiplican por toda la obra. No hay página en la que no haga una alusión a una estación, a un mes, a la mañana o a un «flashback» histórico o personal. Encontramos, por tanto, una novela impregnada del factor tiempo, factor que si bien para el lector llega a ser una constante que tiende a relacionar con el «crono» esclavizador, para Thoreau es un punto de partida, para ese estado de liberación que él busca en sus paseos por los bosques de Concord. Para evitar posibles paradojas y problemas de interpretación, voy a estudiar progresivamente el tiempo en $W$ alden bajo las siguientes acepciones:

-El aspecto trascendentalista del tiempo en Walden.

- Los ciclos de las estaciones en los distintos capítulos de Walden.

-La jornada de THoreau en este entorno vegetal.

En la primera de las acepciones estudio el «fenómeno del tiempo» bajo el prisma del trascendentalismo. En esta primera aproximación, el gráfico nos da una imagen plástica del «presente» al que tiende THoreaU y que no es más que una manifestación del concepto de presente en la filosofía trascendentalista.

El presente para Thoreau es un punto de convergencia del pasado y del futuro. Es un punto que no tiene extensión. Thoreau llega a sublimar este presente y al mismo tiempo nos indica que a través del pasado podemos llegar al «eterno presente», meta a la que también llegamos a través del futuro; puesto que la «golden age» del futuro tiene el carisma de «eterno presente»:

«In any weather, at any hour of the day or night, I have been anxious to improve the nick of time, and notch it on my stick too, to stand on the meeting of two eternities the past and the future, which is precisely the present moment. $\rangle^{2}$

Aquí encontramos la convergencia de dos eternidades en un punto, de cuya convergencia se engendra una tercera que las engloba. Por otra parte en el pasaje al que hago referencia se puede descubrir la clave de

1. “Friday», pág. 217. A Week on the Concord and Merrimack Rivers. Vid. Tho. REAU en la bibliografía.

2. Walden, pág. 254. Vid. Thoreau. 
la filosofía de Thoreau en Walden; «to improve the nick of time», corresponde al ansia de vivir con la mayor intensidad posible el momento presente, momento al que tiende ThoreaU en su viaje al «inner-man».

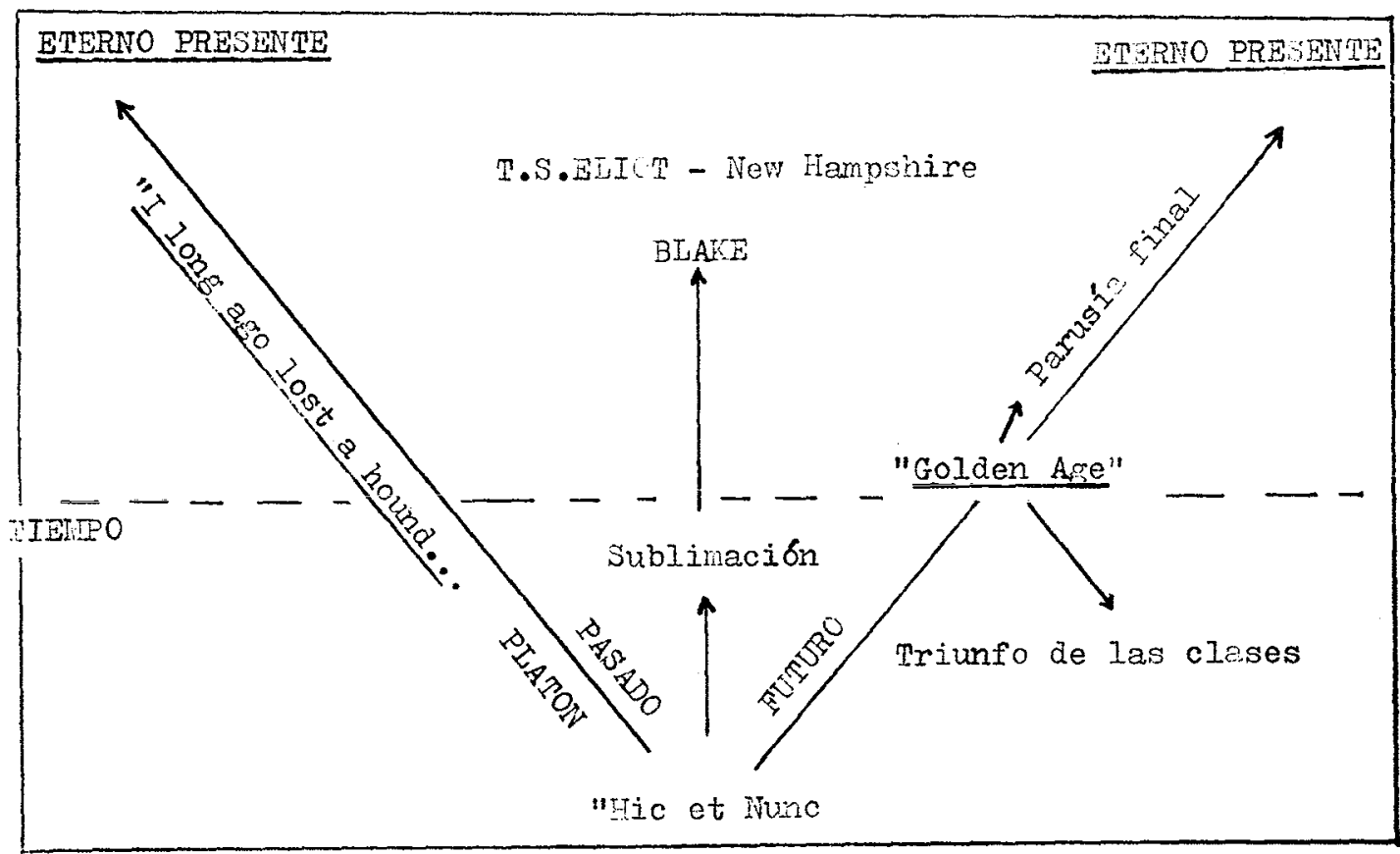

Esta visión trascendentalista del tiempo no empieza y termina en la «young generation» del Boston de 1840, hasta HawTHoRne en The Marble Faun busca una inclusión del tema de la búsqueda en el decorado clásico del paraíso romano ${ }^{3}$, sino que trasciende a otros escritores y a otras épocas. Es normal por tanto, que se repita ya implícita ya explícitamente, el juego del presente, pasado y futuro; juego que aproximadamente un siglo más tarde lo vemos llevado a la poesía de una manera magistral por T. S. ELIOT en Burnt Norton:

«Time present and time past

Are both perhaps present in time future,

And time future contained in time past,

If all time is eternally present

All time is unredeemable. $\rangle^{4}$

3. En el Boston de los días de Thoreau se encuentran figuras de la valía de R. W. Emerson, H. David Thoreau, W. Ellery Channing, Alcott, Margaret Fuller, que tienen como denominador común la filosofía transcendentalista. Estos escritores luchan por encontrar su propia personalidad y de esta manera independizarse del viejo continente europeo. Son profetas del individualismo y de la iniciativa personal en América.

4. Four Quartets. Vid. T. S. Eliot. 
Eliot ve el carácter de eternidad en su irredimibilidad.

Volviendo al gráfico veremos que, para entender ese caminar del presente al «eterno presente» a través de un pasado, sería conveniente leer a Mircea Eliade en el Mito del Eterno Retorno, ya que viene a ser la mejor introducción que podemos tener para comprender la intención de Thoreau en:

«I long ago lost a hound, a bay horse, and a turtle-dove, and am still on their trail.» ${ }^{5}$

¿Qué es lo que ha perdido Thoreau? ¿Qué busca?

Por el contexto en el que aparece esta frase podemos llegar a especificar un poco más y ver que se trata de la búsqueda del «eterno presente». Del presente del que partió el binomio espacio-tiempo. Del presente del que partió nuestra historia, en la que el perro sabueso, el caballo bayo y la paloma torcaz tienen un valor mítico y no son más que la personificación de esas ideas abstractas que trascienden al tiempo. A este presente es al que THoreau trata de llegar en sus esfuerzos por la conquista del tiempo, en su peregrinar cotidiano a la laguna y a los bosques.

En el gráfico vemos cómo del presente llegamos al «presente» teniendo en cuenta el pasado, pero también vemos cómo el futuro converge en el presente y al mismo tiempo tiende al «eterno presente». Presente que es idéntico al presente del que partió la historia, como presente eterno que se escapa a todo tipo de acepciones temporales. A este «eterno presente» a través del futuro es al que Mircea ELIADE llama «edad de oro», por su carácter de epifanía y de anagnórisis. Esta anagnórisis tiene doble interpretación, mientras que los marxistas, esta anagnórisis de la «golden age», la entienden como el triunfo final de las clases, los creyentes la entienden como la unión al «Absoluto», que para los católicos tiene su comienzo en la parusía final.

Una y otra vez a lo largo de la obra vemos a un Thoreau ansioso e inquieto en su actitud de búsqueda. THOREAU no sólo pretende anticiparse al momento en que el día rompe, sino a la misma naturaleza:

«To anticipate, not the sunrise and the dawn merely, but if possible nature herself. $»^{6}$

5. Walden, pág. 255. Vid. ThовеAU.

6. Ibidem, pág. 255. 
En el capítulo II «What I Lived For» habla más explícitamente del presente de su «búsqueda»:

«But all these times and places and occasions are now and here. God himself culminates in the present moment, and will never be more divine in the lapse of the ages.» ${ }^{7}$

Tal vez la mejor introducción a ese «hic et nunc», a ese Dios cuya cima es el momento presente, la encontremos en «Experiencia sicodélica y experiencia mística de Díez Borọue ${ }^{8}$, en cualquiera de esos «trips» de los que él comenta, cuyo punto de llegada es la pérdida de la autocensura, «conditio sine qua non», para participar de la perfecta armonía de Dios - el Dios del que se habla en este contexto es un Dios «sui generis»-. En Walden, Thoreau es un joven más de los que habla Dírz Borque, camina, hace su viaje, busca el «hic et nunc» y de alguna manera llega a ese presente en su cabaña, en sus viajes por el bosque. La sociedad americana del siglo XIX, sociedad esclava del progreso, queda a una milla de distancia si nos olvidamos de la locomotora que bordea œalden Pond. Thoreau, en esos «trips», no se sirve de las drogas ni de los estimulantes, recordemos que en estas fechas hay escritores adictos a las drogas, para participar de la perfección de la armonía divina, le bastará un pozal con el que saque agua del estanque cuando haga frío y bañarse cuando el clima lo permita. La laguna para él tiene un carácter sagrado, «lake of light», «God's Drop»y «Earth's Eye» son las paráfrasis que usa cuando se refiere a la laguna.

THOREAU, finalmente, nos especifica el significado de «vivir el presente» al identificarlo con el «despertar». Un despertar a un mundo sublimado en el que sepamos ver los jardines de Blake o la inocencia de los niños de «New Hampshire» cogiendo manzanas. De este despertar habla unas décadas más tarde WiLliam James:

«...La consciencia racional como llamamos es solamente un tipo especial de consciencia, pero a su alrededor separada de ella por sutilísimas pantallas, yacen formas potenciales de consciencia enteramente diferentes, a las que se puede despertar.» ${ }^{9}$

Es lógico que después de ver el valor que se le da al presente desde este marco transcendentalista, nos planteemos la disyuntiva de si estamos ante un mero ensayo filosófico o ante una obra literaria. Creo que una referencia a Northrop FrYe nos puede dar luz ante este dilema:

7. Ibidem, pág. 309.

8. «Experiencia sicodélica y experiencia mística en torno a San Juan de la Cruz», págs. 23-40. En Papeles de Son Armadans. Vid. Dímz Borque.

9. The Varieties of Religious Experiences, pág. 378. Vid, JAmES, W. 
«Hence every work of literature has both a fictional and a thematic aspect, and the question of which is most important is often simply matter of opinion or emphasis an interpretation.» 10

¿Dónde colocamos a Walden? ¿Cuál de los dos aspectos predomina, el ficticio o el ideológico? Es algo que no voy a comentar, ya que es obvio, aunque el grado del aspecto sea relativo y esté sujeto a la influencia del criterio personal y al grado de énfasis que pongamos en nuestra interpretación; pero lo que sí puedo indicar es que si en The Grapes of Wrath existe el «plot» principalmente para ilustrar el tema de la emigración, algo similar ocurre en $W$ alden con el tema del tiempo; ya que a veces THoreau da rienda suelta a su imaginación y se encuentra viviendo en ese «presente» que le permite entrar y salir en el pasado y en el futuro, le permite desplazarse a aquellas partes del universo y a aquellos tiempos históricos que más le atraen:

«Both place and time were changed, and I dwelt nearer to tohse parts of the universe and to those eras in history which had most attracted me.» ${ }^{11}$

\section{LOS CICLOS DE LAS ESTACIONES}

EN LOS DISTINTOS CAPÍtULOS DE «WALDEN》

Si en el estudio del aspecto transcendentalista del tiempo, termino haciendo una referencia a Northrop FRYE al hablar del tiempo en su aspecto cíclico, la presencia de dicho crítico es todavía más necesaria. Aunque la teoría de los ciclos en N. FrYe tiene un significado más amplio, en este estudio sólo me ciño al plano temporal, con las repercusiones que pueda tener en el entorno de $W$ alden y en la vida de nuestro protagonista.

La primera imagen del desarrollo del ciclo estacional en Walden la obtenemos en este gráfico ${ }^{12}$. Cuando después de la primera impresión

10. «Historical Criticism; Theory of Modes», pág. 53, en Anatomy of Criticism. Vid. FrYe, N.

11. Walden, pág. 302. Vid. ThOREAU.

12. En el gráfico observamos que hay dieciocho casillas que corresponden a otros tantos capítulos. Las letras responden a las iniciales de las respectivas estaciones:

(W), Winter, Invierno

(F), Fall, Otoño

(S), Summer, Verano

(Sp)), Spring, Primavera

Siempre que THOREAU usa el contraste, lo represento por el símbolo ( $\mathrm{x}$ ); para expresar la alusión de cualquier tipo de alusión a las estaciones, utilizo el signo matemático de conjunto vacío por su amplia aceptación, " $\varnothing$ ». 
atendemos al detalle, nos damos cuenta que «winter» es la estación que más frecuencias alcanza; en tanto que «summer» domina en dos capítulos, primavera y otoño uno en cada una, respectivamente. No obstante, THoreau prefiere el sistema del contraste para darle cierta agilidad y movimiento a la obra. Este contraste lo centra de una manera especial en el binomio «winter-summer» con sus «flashbacks»y sus «forwards» a una y a otra estación, respectivamente. De esta manera va desgranando los dieciocho capítulos de $W^{r}$ alden, cargados de experiencia personal, ilusión, de sueños y de utopías, en todos va buscando su «mañana», su despertar. Las estaciones en $W$ alden siguen su ritmo natural y este hombre que a veces llamamos botánico, topógrafo, naturista, sabe llegar a las estructuras más profundas del ciclo de las estaciones, sabe conjugar perfectamente sus reflexiones, sus observaciones e ilusiones al significado de cada estación.

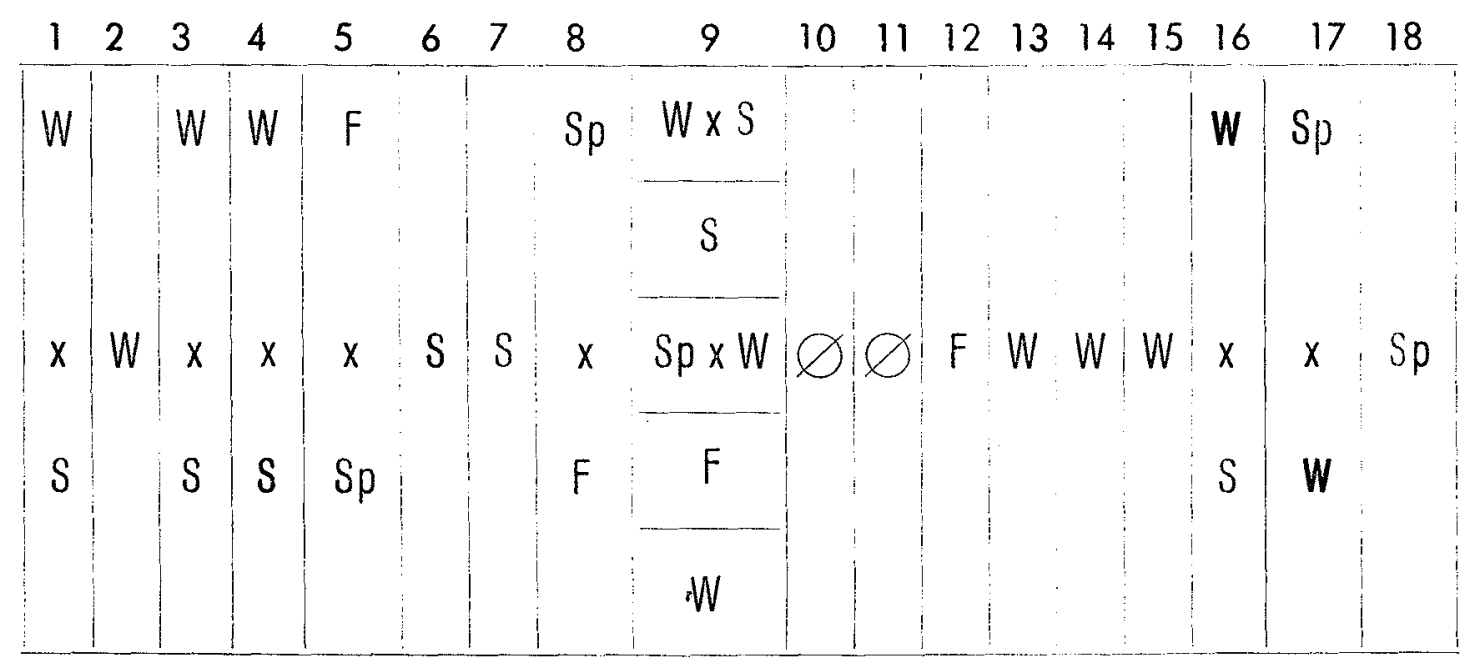

En «Economy» comienza asociando invierno y cabaña; por nuestra parte podemos asociar cabaña con la categoria literaria de «espacio interior». En esta asociación debemos excluir «los espacios cerrados» de Henry JAMES que tienen una relación muy estrecha con el «espacio interior»; la idea de los espacios cerrados nos alejaría de la mentalidad de THoreAu, que constantemente en $W$ alden trata de sustituir la idea de «las cuatro paredes» por la de una naturaleza con horizontes abiertos y despejados. La cabaña tiene valor de «espacio interior» en cuanto que se le puede considerar «zona sagrada» y se la relaciona con el mundo interior de Thoreau, mundo que escapa a las categorías espacio-tiempo.

En su aspecto físico, la cabaña significa protección ante la crudeza de las noches de invierno; en el aspecto interno-espiritual es un símbolo 
de protección ante el descontento que siente THoreau frente a una sociedad que todavía permite la compraventa de esclavos y que usa la ley de la fuerza.

La cabaña en verano tiene el significado de abrigo y punto de referencia. Thoreau se olvida un poco de ella y nos habla de sus paseos por el bosque, del significado de levantarse pronto y de su profesión. THorEaU de algún modo lleva consigo esa categoría del «espacio interior» por las lagunas y bosques de Concord:

«While my acquaintances went unhesitatingly into trade or the professions, I contemplated this occupation as most like theirs, ranging the hills all summer to pick the berries which came in my way.» ${ }^{13}$

Este es el verano para él: «picnics», caminar, observar la naturaleza, coger moras y uvas silvestres, «vivir». Esta es la profesión que THOREAU dice tener frente a la de sus compañeros de Universidad, que andan buscando «una situación en la vida».

El contraste invierno-verano está también, aunque en este caso implícito, en el hecho de levantarse antes de que venga el día. Esto tendría poca transcendencia si el día tuviese la misma duración en todas las estaciones, pero no necesitamos ser astrónomos para saber que los solsticios de verano e invierno tienen repercusión directa en el contraste veranoinvierno y si las noches de invierno son más largas que las de verano, también son más crudas; en verano, la dureza de levantarse viene dada por la hora, en invierno por el clima.

Salvo en "Where I Lived, and What I Lived For», capitulo en el que hace hincapié en la hostilidad y en la desnudez del invierno, Thoreau sigue avanzando a través del binomio invierno-verano a lo largo de esta primera parte hasta llegar a «Solitude». En este capítulo cambia los elementos del binomio y lo que hasta aquí ha sido verano-invierno, ahora es primavera-otoño.

En «Readings» nos presenta el contraste desde un ángulo intelectual; por una parte, la llíada encima de la mesa y las charlas en el círculo tradicionalista, y por otra, la escasez de educación que hay en los Liceos de Concord en invierno. Este sistema, que en cierto modo nos recuerda tesis y antitesis hegeliana, continúa en el capítulo de «Sounds» en los ruidos y chirridos de una locomotora o en los de una máquina de quitar nieves. Los ruidos que emiten ambas máquinas los sitúa en el verano y en el invierno, respectivamente. Esos chirridos rompen indistintamente

13. Walden, pág. 291. Vid. ThoreaU. 
los conciertos musicales de los grillos o de los «whippoorwills» o el silencio de una noche de verano o el de una noche de invierno nevada.

En «Solitude», como ya hemos indicado anteriormente, hay una sustitución de binomio. El contraste de fondo es otoño-primavera. El fenómeno de la lluvia da Jugar a la paradoja soledad-compañía. El silencio que se respira una noche de verano o un día cualquiera de invierno, THOREAU lo ve romperse con los chaparrones de primavera u otoño. La lluvia no tiene en $W$ alden el valor de «intruso» como lo tiene la «máquina», sino que tiene un valor de «compañía». Por la lluvia llega ThoreaU también a descubrir la música del universo. Este hecho, que para él constituye un elemento de participación de la armonía divina, para Chopin es fuente de inspiración en uno de sus «eschorzos».

Cuando miramos al gráfico vemos que «The Ponds» es el capítulo que más nos llama la atención, ya que es un caminar por las cuatro estaciones: Es el capítulo más significativo, no sólo al hablar del tiempo, sino también de las relaciones que guardan los capítulos entre sí, recordemos que el Dr. PÉrez Gállego ${ }^{14}$ lo considera el eje axiológico de Walden. En The Ponds tiene cabida el ciclo perfecto de las cuatro estaciones, que THoreau las mitifica de una manera totalmente personal.

A veces los artistas llegan a interpretaciones dispares en el valor que dan a una determinada estación. Probablemente una de estas interpretaciones dispares gira en torno al invierno en $W$ alden. Mientras que para MALlarmé es la estación de la paz y de la tranquilidad, para THoreau, vista esta estación en conjunto, es la estación de la «purgatio»; por el contrario, la estación de la «purgatio» para Vivaldi en las Cuatro Estaciones es el verano, en ella la bestia y el hombre languidecen y el pino se incendia, en ella la tormenta con sus rayos y truenos llega a enmudecer el canto del jilguero y de la tórtola.

THOREAU, en la interpretación de los valores míticos de las estaciones, no sólo se aparta de la interpretación de otros artistas, sino también de Northrop Frye, el crítico más versado en el tema. Los mitos de THoREAU son personales y guardan cierto paralelismo con el ciclo litúrgico de Adviento, Cuaresma, Pascua y Pentecostés.

Thoreau inicia su ciclo con la recolección de los frutos silvestres en otoño :

«I went a-chesnutting there in the fall, on windy days, when the nuts were dropping into the water and were washed to my feet.» ${ }^{15}$

14. El Héroe Solitario en la Novela Norteamericana, pág. 95. Vid. Pérez Gálleco en el índice.

15. Walden, pág. 375. 
Cuando el problema de la subsistencia está resuelto comienza la fase espiritual de la «purgatio». La «purgatio» de THoreaU son las nieves, fríos y escarchas que le impone la naturaleza. En la primavera llega a la etapa contemplativa de los místicos, en ella nos habla del arco iris y no porque se refleje en la laguna, sino porque la primavera es tan rica en colores que:

«Walden has the color of the iris.» ${ }^{16}$

En este estado de contemplación Thoreau llega a despertar a su «innerman». De la contemplación se pasa a la participación; si en la liturgia cristiana llega esta fase con la Resurrección y Pentecostés, en Walden llega con el verano. En esta estación se baña en la laguna por las mañanas, luego hace excursiones y toma baños de sol.

En «Baker Farm»y en «Higher Laws» THoreau prescinde del encuadre cíclico; a partir de estos capítulos Thoreau vuelve otra vez al otoño y al invierno. El otoño aparece todavía como la etapa previa del invierno, todavía se pueden oír los sonidos onomatopéyicos del «loon», todavía leemos que pasa grandes ratos contemplando los patos en el estanque. Esta etapa es breve y los mismos títulos nos indican cuál va a ser la estación que predomine hasta llegar al «despertar» de la primavera. La narrativa de estos capítulos la constituye una serie de escenas en las que con mayor o menor intensidad aparece el invierno como trasfondo. En esta estación, como compensación al frío atmosférico, Thoreau nos habla del apoyo moral que recibe de uno de sus amigos del círculo transcendentalista, pionero de la desobediencia civil como THoreau, y que aunque aquí no dé su nombre, se trata, de acuerdo a su diario, de Alcott. Otros ecos de sociedad que llegan a su choza son los cazadores con sus jaurías. El fin de la «purgatio» lo anuncian algunas aves de primavera que se adelantan a su estación.

Al llegar «Spring», el invierno queda atrás, con los calificativos de hielo, noche, copos de nieve y frío. Es el momento en que aparece en el entorno de la laguna el binomio invierno-primavera y con este binomio la crisis a todos los niveles, es la crisis que lleva consigo el comienzo de todo nuevo movimiento cíclico. De esta crisis hablan y han hablado mucho los poetas, a ella se refiere T. S. ELiot en The Waste Land:

«April is the cruellest month breeding

Lilacs out of the dead land, mixing

Memory and desire, stirring

Dull roots with spring rain...» ${ }^{17}$

16. Ibidem, pág. 363 .

17. "The Waste Land», pág. 51, en Selected Poems of T. S. Eliot. Vid. Euciot. 
Eliot nos habla de la crueldad de abril para los estériles, puesto que ¿quién es el que no quiere renacer?... Esta crisis del renacer es la crisis del «Phoenix and the Turtle» en Shakespeare, hasta que Ilegan a la «mutual flame».

Para ThoReau también hay crisis y «crueldad» en dejar atrás el invierno:

«As every season seems best to us in its turn, so the coming in of spring is like the creation of Cosmos out of Chaos and the realization of the Golden Age.» ${ }^{18}$

Y el pasar del caos al cosmos es un volver a la vida que implica una crisis. Este fenómeno natural tiene lugar en el paso del invierno a la primavera. La primavera es la mañana, es el despertar, es el rito de entrada en la liturgia de un nuevo ciclo. Este nuevo ciclo es un movimiento más en espiral hacia la «Golden Age», es la manera como Thoreau escapa a] círculo vicioso de Nietzsche.

\section{La jornada de Thoreau en el entorno Vegetal DE «WALden》}

¿Qué hace Thoreau?... ¿Cómo llena su día?... ¿Cuáles son sus actividades?... Son preguntas que el lector se hace ante un hombre que se va a vivir a una choza, abandonando la ciudad, marginándose voluntariamente de la sociedad y no por razones monásticas. Un hombre a quien EMERSON le tributa un último homenaje en las puertas del cementerio de Sleepy Hollow, que a pocas personas se les puede tributar:

«One who surpasses his fellow citizens in virtue is no longer a part of the city. Their Law is not for him, since he is a law to himself.» ${ }^{19}$

Su jornada es simple pero profunda. En líneas generales, sigue este esquema:

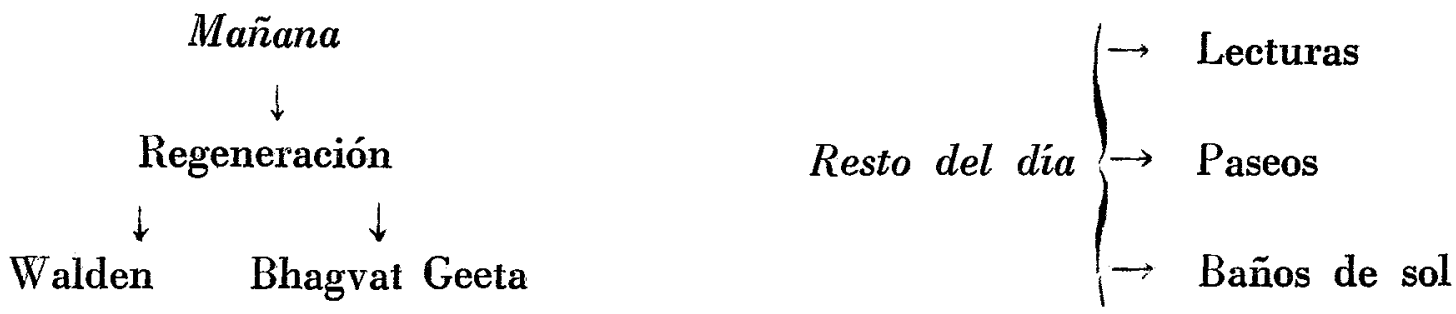

18. Walden, pág. 452 .

19. «Thoreau», pág. 910, en Selected Wrintigs of R. W. Emerson. Vid. Emerson. 
De las implicaciones sociológicas del programa de este hombre, se puede hablar en otra ocasión, en la que se estudie las posibles interferencias y relaciones del código social y de las dietas del «hijo de los bosques». En este estudio consideramos su jornada desde el punto de vista del factor tiempo, más en la vertiente de «tiempo-ocio» que en la de «tiempo-crono».

Un detalle importante en el esquema anterior es el hecho de que sus acciones no están encuadradas en un horario determinado. En el programa la jornada de trabajo como tal, brilla por su ausencia, pero no por ello escapa al estudio de Thoreau y de SKInNER. El behaviorista se mueve en un plano comunitario y presenta como jornada ideal para la comunidad de Walden II, la jornada de las cuatro horas, dedicando el resto del tiempo al «ocio personal». Thoreau se plantea este problema, pero a nivel personal, ya que su comunidad empieza y termina en él:

«For more than five years I maintained myself thus solely by the labor of my hands, and I found that by working about six weeks in a year, I could meet all the expenses of living.» ${ }^{20}$

El plan de trabajo que Thoreau traza en estas líneas tiene mucho de ideal y utópico si se saca del contexto de las circunstancias, puesto que parte de una base de dependencia total de la sociedad de la que él se aleja al marchar a Walden. La sociedad le ha financiado la experiencia de sus dos años de retiro, Thoreau lleva consigo la cultura que ha asimilado viviendo en sociedad, no juega con las materias primas solamente, sino que se sirve de productos elaborados también.

No obstante, si intentamos leer en las líneas anteriores el espíritu que las anima, veremos que hay mucho de positivo en ellas Thoreau identifica sus seis semanas de trabajo con el tiempo que suelen emplear los agricultores en su recolección; respecto al obrero, el programa de THOREAU guarda una relación inversa, ya que el programa de THOREAU tiene una duración aproximada al período de vacaciones de un obrero, y el período de «ocio» de Thoreau la extensión del año laboral de cualquier obrero. «Ocio», tanto Thoreau como Sininner lo entienden en el sentido clásico, en ellos no implica «pereza», «emptiness», sino que equivale a un tiempo personal en el que se puede vivir con intensidad, excluye por tanto la pasividad. El «ocio» de Thoreau tiene una acepción un poco peculiar, que da la impresión de tener una relación muy directa con el silencio de la filosofía del Tao Te Ching, Thoreau no necesita del yoga para conse-

20. Walden, pág. 290. 
guir la liberación del binomio espacio-tiempo, le es suficiente la contemplación de la naturaleza para llegar a un estado de transcendencia similar al de la filosofía del Tao Te Ching.

Fruto de este «ocio» será en Thoreau, lo mismo que en Ghandi, la causa del desarrollo de un pensamiento ideológico que conducirá a la desobediencia civil en ambos.

En el campo de las actividades cotidianas, vemos que describe al detalle las primeras acciones que realiza cada día:

$$
\begin{aligned}
& \text { «Every morning... I got up early and bathed in the } \\
& \text { pond.» }
\end{aligned}
$$

Su visita a la laguna es un ritual. Thoreau va a la laguna a renacer día tras día siguiendo las palabras que hay escritas en la bañera de TchingThang:

«Renew thyself completely each day; do it again and again, and forever again.» 22

Pero no siempre se puede bañar; y cuando llega el invierno, el baño queda relegado a la tarea matutina de ir a buscar agua con el pozal y un hacha. Pero el rito del baño continúa:

«In the morning I bathe my intellect in the stupendous and cosmogonal philosophy of the Bhagvat Geeta.» ${ }^{23}$

Al baño físico le sigue un baño intelectual, un baño de regeneración vital. Esta regeneración implica un renovarse cotidiano «again and again», como reza la bañera de Tching-Thang. La regeneración es alegre y hasta casi religiosa en cuanto tiene la alegría de una nueva acción. Es significativo que en su renovación no vuelva la vista atrás para lamentarse del «wrong doing», del que tan impregnados están algunos escritores contemporáneos del THoREAU en Nueva Inglaterra. No encontramos «flashbacks» en su obra, en los que él mismo se autocensure o tenga remordimientos de acciones que pertenecen al pasado. En la regeneración, en la renovación hay un «caminar hacia algo», para THoREAU se trata de un caminar hacia el «presente», para los hindús hacia el día de Brahama, tendencias que aunque parecen dispares, en realidad no lo son, ya que tanto en el «presente» de Thoreau como en el día de Brahama subyace el concepto de «Absoluto» que, salvo algunas peculiaridades de interpretación, es el punto al que tienden tanto THOREAU como los hindús y demás ideologías religiosas.

21. Ibidem, pág. 303.

22. Ibidem, pág. 303 .

23. Ibidem, pág. 442 . 
A la puntualización de estos primeros ritos de la mañana, se opone la vaguedad con que enumera el resto de sus actividades. Normalmente, las introduce a través de expresiones imprecisas del tipo de «one day», «sometimes», «by spells», «I used to»... Podemos observar como denominador común en estas expresiones la idea de «ocio» desarrollada anteriormente. No obstante, si hacemos un pequeño rastreo a lo largo de W alden descubrimos dos tipos de actividades en Thoreau: actividades de carácter dinámico y actividades de carácter contemplativo. El término dinámico tiene razón de ser en cuanto opuesto a contemplativo, en cuanto que en él se incluyen actividades de orden físico, no en cuanto a su etimología, puesto que «movimiento y crono» son conceptos en entredicho en la obra de Thoreau :

«I worked so deliberately, that though I commenced at the ground in the morning, a course of bricks raised a few inches above the floor served for my pillow at night.» ${ }^{24}$

Al final del día ha tendido la primera hilera de ladrillos de lo que va a ser la chimenea. El ritmo que da a este tipo de acciones nos hace pensar que entran dentro del capítulo de los «hobbies». Son acciones de «ocio» y «participación», no de «competición». Esta distinción nos da pie para situar a Thoreau en el nivel III de consciencia del que habla Charles REICH en The Greening of America y darle el calificativo de profeta de la contracultura. Tanto THokeau como este movimiento se rebelan contra una sociedad que vende a los seres humanos, contra una sociedad basada en la competición, contra una sociedad que pregona la ley de la fuerza y de la violencia.

Thoreau continúa con el ritmo que ha empezado:

«I had an old axe which nobody claimed, with which by spells in winter days, on the sunny side of the house, I played about the stumps which I had got out of by beanfields.»25

En la actividad comentada anteriormente le vemos ocupado todo el día, ahora nos dice que corta leña a ratos. Sólo necesitamos hacer un pequeño análisis semántico para llegar a la idea que Thoreau tiene del trabajo. Nos dice «I played about stumps», aparte del valor figurativo que pueda tener este verbo, parece que THOREAU quiere resaltar aquí el aspecto de deporte, de «hobby», en la tarea que está realizando; prescinde de verbos como «to cut off» o «to chip», que dado el contexto serían más 
apropiados, y en su propósito de desvirtuar el trabajo como sistema usa «to play», de esta manera nos predispone a ver el trabajo bajo la acepción de «ocio»y «leisure».

He comentado dos actividades introducidas por adverbios temporales vagos e imprecisos. Los escenarios de estas dos actividades eran la cabaña y el patio. En la tercera actividad que voy a comentar el escenario es el bosque, en él pasea y en él coge uvas silvestres:

«Sometimes... while the sun was setting, made my supper of huckleberries and blueberries on Fair Haven Hill, and laid up a store for several days.» 26

Poner ladrillos en el hogar, cortar leña en el patio y coger uvas silvestres en sus paseos, son actos que si no abarcan toda la gama de posibles actividades que pudieran comentarse, sí constituyen tres tipos de acciones simbólicas y representativas que nos dan una idea de cómo consume el resto del día, después de los ritos matutinos.

Queda por hacer una alusión a las actividades de carácter contemplativo de las que se comentan en el esquema. En ellas ThовеAU deja de ser actor para pasar a ser mero receptor:

«I used to resort to the north-east side of Walden which the sun... made the fireside of the pond.» ${ }^{27}$

Sigue sin abandonar la vaguedad del «used to», el tiempo lo subordina a sus acciones. Se libera del programa y, por tanto, no es esclavo ni del fenómeno tiempo, ni de los actos que tiene que realizar. Vive el «hic et nunc» con intensidad y sin subordinación.

\section{LA MAÑNA}

Más que hacer una síntesis final, quisiera hacer un breve comentario sobre esta palabra que tan significativa es para THOREAU.

¿Qué es la mañana en Walden? Es la «deep structure» de la laguna, es la expresión del significado del Pond. La mañana es el despertar en el sentido que lo entiende Thoreau:

«All intelligences awake with the morning.» 28

28. Ibidem, pág. 304. 
Es el despertar al «inner-man». En este ansia de despertar al hombre interior, Thoreau intenta escuchar día tras día el poema de la creación que sopla el viento de la mañana y que pocos son los oídos que lo pueden escuchar :

«The morning wind forever blows, the poem of creation is uninterrupted, but few are the ears that hear it.» ${ }^{29}$

El poema de la creación, la música de las esferas y la armonía del universo llegan a los oídos de Thoreau en el entorno vegetal de $W$ alden cuando el día rompe; en la crisis del despertar a un nuevo día, el invierno, la noche, han quedado atrás. Thoreau vuelve a dar sus primeros pasos en la mañana, de nuevo inicia la búsqueda de ese «eterno presente» en su despertar progresivo a la armonia del universo En la mañana siguen buscando el caballo bayo, el perro sabueso y la paloma torcaz.

\section{BIBLIOGRAFIA}

Brooks, V. W., 1936. - The Flowering of New England. The Modern Library, New York.

Cassirer, Ernst, 1971. - Filosofía de las Formas Simbólicas. Fondo de Cultura Económica, México.

Díez Borque, J. M.a ${ }^{a}$ junio 1972. - «Experiencia sicodélica y experiencia mística en torno a San Juan de la Cruz». Papeles de Son Armadans, núm. 78, Palma de Mallorca.

Eluade, Mircea, 1972. - El Mito del Eterno Retorno. Alianza Editorial, Madrid. 1967. - Lo Sagrado y lo Profano. Guadarrama, Madrid.

Eliot, T. S., 1970. - Selected Poems of T. S. Eliot. Faber and Faber, pp. 127, London. 1968. - Four Quartets. Faber and Faber, London.

Emerson, W. R., 1950. - Selected Writings of R. W Emerson, ed. by Brooks, A. The Modern Library, New York.

Frye, Northrop, 1970. - Anatomy of Criticism. Atheneum, New York.

JAMES, W., 1936. - The Varieties of Religious Experiences. The Modern Library, New York.

MAtThiessen, F. O., 1968. - «From Emerson to Thoreau», en American Renaissance. Oxford University Press, London.

Pérez, C. G., 1967. - El Héroe Solitario en la Novela Norteamericana. Editorial Prensa Española, Madrid.

Thoreau, H. D., 1937.-The Works of Thoreau, Selected and edited by H. Seidel. Houghton Mifflin Company, Boston.

Srinner, B. F., 1972. - Walden II. Macmillan, New York.

TarmnI, I. K., 1974. - Man, God and the Universe. The Theosophical Publishing House, London.

Prabhavananda y Isherwood (translated), 1951. - The Song of God Bhagavad Gita. The New American Library, New York.

29. Ibidem, pág. 360 . 